\title{
Myths and Realities of University Governance
}

The traditional view of academic governance that the university is a self-governing community of scholars is a myth. The fact is there are a number of groups, both inside and outside the institution, involved in governance, each with its own interests and in conflict with one another. Recognizing this fact, we can approach governance realistically and devise a reasonably workable system which will deal with the paramount issue of jurisdiction.

\section{$\mathrm{T}$} HIS IS A DIFFICULT TIME to discuss university governance, especially if one would like to be at all definitive. We are in the midst of a transition from a rather long period of "growth and grandeur," to use Kenneth Boulding's apt alliteration, to a highly uncertain, if not declining, future. The dimensions of our uncertainty are generally familiar. Our financial problems are so well known that they even have a more or less official name, "the New Depression in Higher Education." The press no longer pays much attention to us, and when it does it is mostly to announce that we have lost public confidence. ${ }^{1}$ Enrollments are dropping, faculty positions are scarce, and tenure is being attacked from all sides as a result. Above all, we generally seem to be thoroughly unable to respond effectively to the buffeting we have been taking, and in part, this is a problem of governance. A time

Dwight R. Ladd is professor, Whittemore School of Business and Economics, University of New Hampshire. This article is based upon an address delivered at a meeting of the Association of College and Research Libraries, July 7, 1974, in New York. of stress requires efficient and effective decision making, and few would argue that either term describes academic decision making. Our typical governance procedures are simply not suited for the present time of deep uncertainty and rapid change. Yet we seem unable to make our governance procedures more effective, because we cling to the traditional view of ourselves as a "self-governing community of scholars." This self-view involves some very basic myths: that we are self-governing, and that we are a community, let alone a community of scholars. More than one social organization has sustained itself and prospered on the basis of myths, but in our case the myths have outlived any usefulness they may have had. They prevent us from recognizing that for better or worse the university is made up of and functions for a congeries of interest groups which do not share a basic consensus about the institution's values, goals, and processes, and who are quite regularly in conflict. Failure to recognize this keeps us from attempting to devise governance structures more appropriate to our character and, therefore, far more likely to provide the efficient and effective decision making these troubled times call for. 


\section{The Myth of Self-Government}

Perhaps the most dangerous of our myths is that governance is basically the function and prerogative of "insiders" -faculty, academic administrators, students, professional staff, and so on. Most of our discussions about governance have to do with the nature and extent of participation by one or another of these groups. We ignore the many "outsiders"-state coordinating boards, legislatures, governors, federal officeswho are potentially, and increasingly, in practice, a part of governance. We also tend to ignore the important class of "in-betweeners," primarily our boards of trustees. Ignoring these groups when we deal with governance is dangerous, because while we argue among ourselves about our jurisdictions and our prerogatives, they may end up doing the actual governing.

In its 1973 report on governance, the Carnegie Commission observed that we are in the midst of a "transfer of authority from the campus to outside agencies."2 The outsiders are indeed making more of the decisions traditionally made on campus. Whether a particular institution will offer instruction in a particular subject is now often decided by a coordinating board and not by the institution itself. Legislatures regularly consider, and sometimes pass, regulations of faculty teaching loads and minimum class sizes. Nor are publicly controlled institutions the only ones experiencing this transfer of authority. For example, "Affirmative Action," whatever its merits, is a very direct infringement on what is surely one of the most fundamental of all professional prerogatives, control over admission to the guild. Affirmative Action applies equally to public and private institutions. Nor should one ignore the increasing tendency of "inside" issues to be referred to the courts for adjudication-a transfer of authority to outsiders which may be rather more subtle than direct action by a legislature, but which may also be rather more difficult to reverse if reversal should seem desirable. Legal precedents resulting from court decisions do not just go away.

To recognize this shift in the locus of governance is not to know what to say or to do about it. There really are no relevant experiences or parallels on which to draw. One thing can be said with a good deal of confidence: If the shift of authority to outsiders becomes very widespread we will be in a very new and different ball-game. Leaving aside trustees, the in-betweeners discussed below, decisions about basic educational policies, standards, professional activities, and so on have always been made by insiders, primarily academic administrators and faculty. Whatever else their disagreements, these insiders have generally shared an understanding about certain traditional norms and values; but with a significant shift of power to outsiders, this understanding would, for better or worse, be lost. There are some questions which are unanswerable, some actions which are not justifiable in any conventional, nonacademic sense, yet which are answered and justified within the academy by those who are initiated into its true faith. For example, Why does Professor X teach only one course to just four students? Why does the library have to own a copy of the Bay Psalm Book? Why are there courses in classical Greek when only seven students take it? Of course, such questions should be asked, and our failure in recent times to have asked them often enough is surely a major reason why we are now in trouble. But even when they are asked, the reasoning underlying the answers is deeply rooted in the university culture, a culture not readily accommodated to the practical world of affairs. It is not to criticize outsiders from that practical world to observe that values which are self-evident to us may not be self-evident to them, 
and perhaps cannot be made so.

It has not been my intention to praise or condemn this transfer of authority to outsiders, but simply to point out that while we in the academy struggle over our jurisdictions, we may find (when and if we settle them) that there will be nothing of importance to exercise jurisdiction about. In this as in many other matters, we are alarmingly like the railroads who for years have competed busily among themselves for business-so busily that they completely ignored the trucks, pipelines, and barges that emerged from changing technology and took away most of the railroads' business while they warred among themselves. I am enough of a traditionalist about higher education to hope that this does not happen to us. We did get fat, careless, and enamored of our own importance during the glory years, and some difficult drying out is inevitable. Surely we must pay more attention to the needs of all our constituents and the resources of our supporters. However, there are some vital, albeit very fragile, aspects of higher education whose protection and nurture require a very special kind of understandingan ideal, perhaps-which is not likely to be a part of governance by outsiders.

Trustees are also involved in this transfer of authority. As the Carnegie Commission observed, there was until quite recently a general consensus that boards of trustees should watch out for the money, care for grounds and buildings, and appoint a good president. ${ }^{3}$ Consensus there may have been on this limited role, but no longer. In a recent poll, 599 board chairmen agreed that "trustees should assume a bigger role in handling such issues as faculty workloads, tenure, and even the content of the curriculum." 4 Ralph Besse, a lawyer and member of the former Carnegie Commission, asserted, "The very essence of the university is wrapped up in these two phrases-'what is taught' and how it is taught.' . . . I believe that the responsibility of trustees in both areas is very great. . . ."5 According to reporter Malcolm Scully, the trustees to whom Besse spoke agreed that they "must become more involved in the academic and curricular issues that faculty members have seen as their own territory."6

It is virtually certain that in the coming years trustees will be more involved in governance than most of them have been in recent years, but their greater involvement may not be as contrary to traditional norms as I have suggested outsiders' may be. This is why I refer to trustees as in-betweeners. Trustees are rather more likely to identify themselves with the institution than with outside constituencies, more likely to accept some of the unique values of the academy. But even if they do, assumption of active jurisdiction by trustees over "inside" affairs will create a very different environment from what most of us have long been used to.

\section{The MYTH OF CoMmunITY}

The second half of the myth is the myth of community and its operational handmaiden-consensus. Membership in the community has steadily been expanded, well beyond any meaningful limit; and consensus about institutional goals, values, and processes has largely been shattered. Both changes largely result from the same underlying phenomena, but they need to be discussed separately.

Whether or not the community of scholars ever did exist in fact, it has been disappearing for some time. It partly disappeared in the smoke of Jencks and Riesman's Academic Revolution: Rapid growth, increasing diversity and specialization, and movement of faculty outside the ivory tower into the world of affairs all undermined whatever community may have existed among the faculty. It became rather thoroughly lost when we began, in the 
late 1960s, to expand our definition of community to include students, professional staff, and more. These various groups may well have a right to a voice in university decision making, but it is surely as groups with unique interests that they speak, and not as members of a community of scholars. Their unique interests preclude, in most cases, the basic consensus which is the operational basis of a true community.

With very rare exceptions, universities have always had faculty and students, and through most of history they have been two quite separate interest groups, generally engaged in some form of conflict. ${ }^{7}$ For one thing, they are, and in some sense must be separated by the certifying function. As long as the degree is awarded on the basis of achievement defined and measured by designated experts, there cannot be true community of students and faculty. Certification involves faculty in a kind of authority and power over students which cannot be wished away. For another thing, and I know that this has almost become cliché, students and faculty do have different time perspectives. Student attachment to the university is, except for those few preparing for academic careers, quite transitory, whereas the faculty member normally devotes a lifetime to it. While it is, I think, another, minor myth that faculty members have only the long-run welfare of the institution at heart (we are about as selfcentered as any other group), it is generally the case that faculty have a broader and deeper perspective of the past and are better able than students to think of the institution's future in a long perspective. (This does not mean that faculty will always act with the best long-run future of the institution in mind. Our recent responses to proposals to cut out tenured positions in the face of declining enrollments have not always been exemplary; but at least the potential is there.)
None of this is to denigrate the value of listening to and consulting with students. I think most of us learned in the late 1960 s that they did have something to tell us about what higher education and its institutions had become. It is to say that because of the university's certifying function, because certification is the primary interest of most students, because of differing time perspectives, and from that, a different relationship to the institution, faculty and students cannot make up a true community.

Universities have not always had administrators, but most American universities have had them during their history, and today administrations come in battalion or regimental sizes. It is fashionable among many faculty to condemn the growth of administration, but most of what administrators do has to be done, and I am not aware of any great willingness by faculty to give up the time required to do them. We have institutions with student bodies numbering in the tens of thousands and faculties in the thousands. Libraries of a million or more volumes are not uncommon. The trivium and quadrivium have been joined in the curriculum by psycho-linguistics, biophysics, advanced basketball, and a host of others, while expensive computers and electron microscopes have joined paper and chalk as commonplace tools of instruction and research. There is a constant need to raise money, along with a growing number of ways in which its use must be accounted for. There is a parking problem. The contemporary university is simply too large, too complex, and too expensive to be run by part-time amateurs, however gifted.

Compared with faculty and students, it is surely easier for faculty and administrators to form something of a community if for no other reason than that most administrators are recruited from faculty ranks. By and large, they share an understanding of academic 
mores and traditions, and they have much the same time perspective. Nevertheless, there is, inevitably, something of an employer-employee relationship involved, however much it may be camouflaged by the rhetoric and social behavior of colleagueship. Furthermore, administrators work in a hierarchy much more akin to that of industry and government. They are much more directly accountable to superiors and outsiders than are most faculty members, especially in a short-run sense. I can spend years and years working on "my book," but my dean has to develop and stick with an annual budget, has to respond to unhappy or angry parents, and has to placate various outsiders (sometimes even me) who think we should or should not be doing this or that.

Further to confound the vision of community is the growing army of professional staff on most campuses. Computation centers, counseling centers, budgets and reports, fund-raising, neighborhood relations, audiovisual centers, and so on and so on do not just happen. They require trained and skilled professionals who have a professional stake in the institution. Yet I think it cannot be denied that there is a gulf between professional staff and faculty. The activities in which professional staff are engaged are, in the eyes of most faculty, ancillary to the mainstream activities of teaching and research. Furthermore, professional staff inevitably have a style different from that of most faculty members. Rather than the endless discussion and continued refinement of intellectual subtleties so characteristic of faculty activity, professional staff people generally have to make decisions in a timely fashion on the basis of the best information available. Businessmen have long criticized faculty members as "dreamers who never met a payroll." In a sense, staff professionals could have the same general view of faculty.
I will not attempt to add to what I have already said about outsiders. They do participate in institutional governance, yet there is no way I can see in which they can be made a part of a "community" in the operational and ideological sense of that term.

\section{The Myth of Consensus}

With or without considering outsiders, we have so expanded our notions of legitimate participation and membership, that we simply do not have a community as a viable basis for governance. Furthermore, even if we could agree on a workable basis for membership in the community we would not have gained very much, because community is effective as a basis for governance only if there is some kind of consensus about the basic goals, values, and processes on which the community rests. With such a basic consensus, most issues can be resolved through reasonable discussion, rather than through the avowedly political process of forming tactical alliances, devising parliamentary strategies, and so on. ${ }^{8}$ If we ever did have such a consensus about academic goals, values, and processes, it has been shattered by the academic revolution, the student movement, and the loss of public (and perhaps self) confidence.

Certainly the primary educational objective is scholarship. This is an objective which reflects such values as rational thought and behavior, objectivity, personal detachment, belief in the cognitive, and the authority of knowledge. With those values dominating, the teacher is placed at the center of the learning process, and teaching is primarily subject-centered. Most campuses, however, have at least small groups of faculty, students, and others who see personal development of the student as the principal educational goal. This goal involves such values as belief in the personal and subjective, experiential learning, the importance of feelings, 
and the authority of every individual being. Such goals and values tend to be reflected in teaching which is studentcentered, and which is more concerned with values and attitudes than with facts and theories. And increasingly in the present economic climate, there are many on most campuses whose educacational objective is career preparation. (My son, a junior at Brown, recently characterized such students as "uptight, preprofessionals.") These people value the practical over the theoretical and relationships with practitioners and the outside world over academic and intellectual contacts. Service, rather than scholarship or personal development, tends to be their guiding concept. ${ }^{9}$ The foregoing, brief description of different value sets found in contemporary academia has been cast in terms of faculty, but there is an increasing tendency for groups of faculty, students, and administrators to coalesce around a program reflecting one or another of these. What this does, of course, is to add still another set of unique interest groups which cuts across the more or less functional groupings which were described earlier.

Whether consisting of faculty alone or of faculty and other adherents, these three groups share very little consensus about educational goals, values, and processes. They may be, and regularly are, engaged in debates and discussions about curriculum, standards, grading, and so on, but they rarely achieve lasting decisions. The cognitively oriented chemist will simply not recognize encounter groups as a legitimate academic pursuit. The practical-minded accountant or engineer will accept applied mathematics, but will not value the abstractions and aesthetics of theoretical mathematics. The student-centered professor will tend to reject lectures, prescribed reading lists, and objective tests. When these groups come together to make institutional decisions about aca- demic matters, even interminable discussion will not produce a decision acceptable to all. Because they assume community and consensus where none exist, our governance processes tend to be characterized by endless, and rarely reasonable, discussion and few real decisions on matters of consequence. Perhaps we are lucky that more decisionmaking authority has not moved to outsiders.

\section{A Realistic Approach to Governance}

What we have, then, is a kind of interest group pluralism in the university with several groups of insiders, the trustees as in-betweeners, and several groups of outsiders, each with a somewhat unique stake and unique interest in the institution. On rare occasionsa Martian invasion might be one-these diverse interests would come together around a basic consensus about the university, but most of the time two or more groups will be in conflict. Our governance structure should reflect this. It should be designed to deal with conflict rather than to ratify consensus, which is what it has generally been designed to do. We need to have a governance structure which recognizes that we are not a "self-governing community of scholars," that outsiders do have a legitimate voice in our affairs, that conflict rather than consensus is our normal posture, and that a rapidly changing environment requires timely and efficient decision making.

I believe it is possible to devise a reasonable workable system for these conditions, if one thinks only in terms of insiders and trustees. I confess that I see no effective way of including outsiders. Such things as state coordinating boards are, in reality, the antithesis of institutional self-government. They came into being to correct distortions and excessive costs in the system and to prevent future distortions and excesses, both of which result from the self-cen- 
teredness of individual institutions. Some government by outsiders is bound to exist for a very long time to come. If most of us insiders believe, as I do, that this should be limited, I believe that the most and best that we can do is to put our own house in order and demonstrate that we can make policies and decisions which are sensitive to the needs and constraints of outsiders, and that we can do so effectively.

Effectiveness begins with recognition that we are not a community, that we are a collection of diverse interest groups with separate and distinct goals and values. We cannot define the one true path to follow through any amount of reasonable, community discussion. Each group wants to follow its own path with a minimum of diversion, and therefore jurisdiction becomes the paramount issue. Who decides is often as important as what is decided. In a true community, jurisdiction is not an issue, and because we cling to the myth of community, we often are involved in unstructured debates about jurisdiction when we think we are debating the substance of issues. The results are rarely effective.

Broadly speaking, there are two ways of dealing with the jurisdictional issue. One approach is to create a broadly representative body whose sole function would be to decide who decides. The other approach would be to attempt to solve the jurisdictional issue once and for all by centralizing all decision making in an acceptable way.

The first approach is to create a body representing all of the interest groups which would have as its sole function deciding who decides. The group could function either in a steering or appellate role. In the first case, all issues requiring decision would be referred to this body, which after reviewing the issue and possible solutions would rule that it would go to an academic subunit (e.g., a college or school within a univer- sity), to the faculty senate or its equivalent, to a similar student group, or, perhaps, one representing professional staff. In many, perhaps most cases, the administrative hierarchy would be the appropriate locus for the particular decision. Obviously, some issues would be referred to more than one group, and some rules for resolving split decisions would be needed. If the jurisdictional body functioned in an appellate role, it would decide on jurisdiction only when some interest group challenged the assumption of jurisdiction by another such group. Which approach, steering or appellate, is most appropriate would depend on the situation in a particular institution.

To the best of my knowledge, no university has developed such a system, though my own is presently contemplating the introduction of something very much like it. Some obvious difficulties are defining the interest groups which should be represented in such a body, and especially recognizing and including interest groups or constituencies which develop after the body has been formed. There is also the possibility that one or another of the interest groups would not accept a decision denying it jurisdiction. To that latter objection, I can only reply that unless we are willing to accept some level of decision as final and binding, there is no point at all in talking about governance systems. Raw power would then become the arbiter.

Centralization of decision making would tend to eliminate jurisdictional quarrels, and I believe it can be done without a real violation of whatever aspects of community and consensus remain. What is involved is the adaptation of the idea of responsible government to the university. The trustees would select a chief executive officer who would have de facto power of decision within the university, which power includes, of course, the power to dele- 
gate. The chief executive officer would be responsible for the use of full power in the sense that any of the recognized interest groups could at any time indicate a lack of confidence in the decisions of the chief executive, following which his or her performance would be reviewed and his or her tenure either terminated or continued by the trustees. Procedural arrangements would no doubt differ somewhat among institutions but should always insure that legitimate grievances would be heard while safeguarding against purely capricious charges of no confidence.

This system would require that boards of trustees be reconstituted so that all of the legitimate interest groups would be represented in its membership, for only if all have a voice in the selection of the chief executive and in reviews of his performance, would the legitimacy of his power be accepted. It would also require acceptance by trustees that its principal functions would be selection and review. Within the institution, the same arrangements could, and no doubt should, apply to subordinate administrative officers to whom the chief executive would delegate power.

In some measure, many institutions are working toward this system by appointing presidents, provosts, deans, etc., for fixed terms, and reviewing performance at the end of those terms. What has not yet happened, as far as I know, is that the various interest groups have been willing to relinquish whatever vestiges or fantasies of power they have. (This may be happening, too. I have recently been involved with two institutions which faced the absolute financial necessity of eliminating some faculty positions. In both cases, the administration presented the faculty with the requirement and asked the latter to make the decision. After deliberation, due and undue, both faculties returned to the president saying, in effect, "You do it. We can't.")
Properly instituted, I believe that such a system would provide safeguards against arbitrary and unchecked power, because the board which would make the decisions on appointment and removal would be characterized by legitimacy and would be relatively detached from the day-to-day affairs and passions of the institution. Nor would involvement and consultation be eliminated. The extreme complexity of the modern university makes nonconsultative government virtually impossible. No executive could possibly know about and understand all of the diverse things going on. He would have to have advice and counsel from those who do have the necessary familiarity and would seek it. Without it, he would surely increase the risk of making badly conceived decisions which could lead to his recall and removal from office. In practice, the function would be much like that of the jurisdictional body described above. The chief executive would decide which of the constituencies should be consulted or delegated to for any particular issue, and would conduct the necessary dialogue with them.

\section{Conclusion}

I have no doubt that experience would indicate many necessary modifications in either of these proposals, but I argue that they or something quite like them must be tried. The longer we cling to governance systems based on the myth that we are a community with a widely shared consensus about educational goals and values, the longer we will continue to fail to respond to a changed and changing environment because we will continue to be bogged down in jurisdictional disputes. And the longer we behave in that way, the greater the risk that we will lose all vestiges of reality behind the other part of our myth-self-government. Those outside the academy are clearly impatient with us. They may already have decided that 
we cannot govern ourselves effectively. I prefer to think that we still have some time to shed our myths and prove that we can.

\section{REFERENCES}

1. George N. Bonham, "Change and the Academic Future," Change 6:9-12,64 (June 1974).

2. Carnegie Commission on Higher Education, Governance of Higher Education: Six Priority Problems (New York: McGraw-Hill, 1973), p.1.

3. Ibid., p.31-36.

4. Malcolm G. Scully, "Many Trustees Seek to Assert More Control," Chronicle of Higher
Education 8:1-2 (May 6, 1974).

5. Ralph M. Besse, "All the King's Men," AGB Reports 16:4 (May/June 1974).

6. Scully, "Many Trustees," p.2.

7. Frederic Rudolph, The American College and University (New York: Vintage Books, 1962); Laurence R. Veysey, The Emergence of the American University (Chicago: Univ. of Chicago Pr., 1965).

8. Richard C. Richardson, Jr., "Governance Theory: A Comparison of Approaches," Journal of Higher Education 45:344-54 (May 1974).

9. Dwight R. Ladd and Allan R. Cohen, "The Need for New Organizational Structures," in Reform of Undergraduate Education, ed. B. Sagan (forthcoming).

\section{INSTRUCTIONS FOR AUTHORS}

Manuscripts of articles submitted to College \& Research Libraries are to be sent to the Editor: Richard D. Johnson, James M. Milne Library, State University College, Oneonta, NY 13820. Manuscripts should be in two copies and typed in double space. The title, name and affiliation of the author, and an abstract of 75 to 100 words should precede the article. Notes are to be consecutively numbered throughout the manuscript and typed in double space on separate sheets at the end. The journal follows A Manual of Style, 12th ed., rev. (Chicago: University of Chicago Press, 1969) in matters of bibliographic style; and recent issues of this journal may be consulted as well. 